\title{
Epithelial cell identity in hyperplastic precursors of breast cancer
}

\author{
Danila Coradini ${ }^{1 *}$, Patrizia Boracchi ${ }^{1}$, Saro Oriana ${ }^{2}$, Elia Biganzoli ${ }^{1}$ and Federico Ambrogi ${ }^{1}$
}

\begin{abstract}
Introduction: In the adult human breast, hyperplastic enlarged lobular unit (HELU) and atypical ductal hyperplasia $(\mathrm{ADH})$ are two common abnormalities that frequently coexist with ductal carcinoma in situ (DCIS). For this reason, they have been proposed as the early steps in a biological continuum toward breast cancer.

Methods: We investigated in silico the expression of 369 genes experimentally recognized as involved in establishing and maintaining epithelial cell identity and mammary gland remodeling, in HELUs or ADHs with respect to the corresponding patient-matched normal tissue.

Results: Despite the common luminal origin, HELUs and ADHs proved to be characterized by distinct gene profiles that overlap for 5 genes only. While HELUs were associated with the overexpression of progesterone receptor (PGR), $\mathrm{ADH}$ s were characterized by the overexpression of estrogen receptor 1 (ESR1) coupled with the overexpression of some proliferation-associated genes.

Conclusions: This unexpected finding contradicts the notion that in differentiated luminal cells the expression of estrogen receptor (ER) is dissociated from cell proliferation and suggests that the establishing of an ER-dependent signaling is able to sustain cell proliferation in an autocrine manner as an early event in tumor initiation. Although clinical evidence indicates that only a fraction of HELUs and ADHs evolve to invasive cancer, present findings warn that exposure to synthetic progestins, frequently administered as hormone-replacement therapy, and estrogens, when abnormally produced by adipose cells and persistently present in the stroma surrounding the mammary gland, may cause these hyperplastic lesions.
\end{abstract}

Keywords: Mammary epithelial cell identity, Hyperplastic enlarged lobular unit, Atypical ductal hyperplasia, Ductal carcinoma in situ

\section{Background}

According to the model proposed for breast cancer progression, normal epithelial cells progressively accumulate molecular alterations that result in a series of histologically identifiable, even if non-obligate, cancer precursors. Among the precursors earliest in the progression is hyperplastic enlarged lobular unit (HELU), a common abnormality in the adult female human breast [1]. HELU consists of an abnormal enlargement (often up to 100fold) of normal terminal duct lobular unit (TDLU) from which it evolves. Histologically, the epithelial cells that line these dilated lobules appear increased in number

\footnotetext{
* Correspondence: danila.coradini@gmail.com

'Department of Clinical Sciences and Community Health, Medical Statistics, Biometry and Bioinformatics, University of Milan, Via Vanzetti 5, Milan 20133, Italy

Full list of author information is available at the end of the article
}

and changed in morphology with the transformation of low cuboidal epithelium to irregular tall columnar epithelium. The transformation may be associated with atypia, which is characterized by the presence of round to ovoid nuclei not perpendicularly oriented to the basement membrane, and an increased ratio of nuclear to cytoplasmic [2].

Observational studies have indicated that HELU frequently coexists with more complex proliferative lesions such as atypical ductal hyperplasia (ADH) and low-grade ductal carcinoma in situ (DCIS) [3], suggesting it occurs as the first step in the biological continuum toward breast cancer [4]. For this reason, the presence of HELU has been proposed as a potential valuable risk factor to be thoroughly investigated and monitored [5], though clinical evidence has indicated that only a small fraction of HELUs actually progress to invasive breast cancer [6]. 
Among the early events required for neoplastic transformation of a mammary epithelial cell, there are perturbations in cell type identity. This term refers to the predetermined, tissue-specific set of genes that characterizes every cell within a multicellular organism. These genes are conserved during DNA replication and mitosis so that daughter cells retain the differentiated cell type of the parental cell (cell memory). Preservation of cell identity depends on a class of proteins that are collectively termed maintenance proteins [7]. Studies have shown that maintenance proteins, among which Trithorax- and Polycomb-group proteins are the best characterized, act in a somatically heritable but DNA-independent manner (i.e., epigenetically) and regulate gene expression through DNA methylation, histone modification, and chromatin remodeling $[8,9]$. Because of their recognized role in the control of cell identity and mammary gland remodeling, perturbations in maintenance protein expression can affect cell identity and trigger neoplastic transformation [10].

Here we used publicly accessible microarray datasets to compare, in a series of HELUs from noncancerous adult breasts and corresponding patient-matched, normal TDLUs, the expression pattern of genes experimentally recognized to be involved in regulating cell identity and mammary gland remodeling. Furthermore, in agreement with the hypothesis that HELU may represent the biological precursor of ADH to be used for the early assessment of breast cancer risk, we compared the gene expression profile of HELU with that of a series of putative invasive breast cancer precursors, namely ADH and DCIS, and corresponding patient-matched, histologically normal tissue.

\section{Methods}

\section{Tissue samples}

As described in the original article by Lee et al. [11], well-developed, single-layer type HELUs with minimal nuclear atypia and paired normal TDLUs were derived from 8 women's noncancerous breast tissues. In each formalin-fixed, paraffin-embedded tissue biopsy, HELUs and TDLUs were isolated by laser capture microdissection. Gene expression was determined using U133-X3P Human GeneChip oligo-based microarray (Affymetrix, Santa Clara, CA, USA) and the corresponding microarray dataset was publicly available at the ArrayExpress web site (http://ebi.ac.uk/arrayexpress/) under accession number E-GEOD-7377.

To compare the gene expression profile of HELUs with that of ADHs and DCISs, we used another publicly accessible dataset containing microarray data from coexisting patient-matched samples of ADH and DCIS lesions and corresponding histologically normal tissue, isolated by laser capture microdissection from surgical specimens of untreated patients with estrogen receptor (ER)-positive (immunohistochemically evaluated) sporadic breast cancer [12]. Gene expression was determined using HG-U133A Human GeneChip microarray (Affymetrix) and the corresponding microarray dataset was available at the ArrayExpress web site under accession number E-GEOD-16873.

\section{Gene set selection}

After an extensive literature review, we established a panel of 369 genes that included genes associated with establishing and maintaining cell identity and with mammary gland remodeling, or that were involved in cell fate decision, cell growth control, cell polarity and adhesion, and steroid and transforming growth factor $\beta$ (TGF- $\beta$ ) signaling. Of these 369 genes, 8 had no corresponding probe sets on the U133-X3P GeneChip and 40 had no corresponding probe sets on the HG-U133A GeneChip. Therefore, for the E-GEOD-7377 dataset, the gene set was actually composed of 361 elements for 842 Affymetrix probe sets, whereas for the E-GEOD-16873 dataset, the gene set was actually composed of 329 elements for 639 Affymetrix probe sets. A total of 326 genes were present in both datasets. GeneAnnot system v2.2 (http:// bioinfo2.weizmann.ac.il/geneannot/) provided information about the quality of connection between each probe set and the corresponding gene in terms of sensitivity and specificity [13]. Specifically, the sensitivity, defined as the fraction of probes in a probe set that match a respective gene, is the number of matching probes in a given probe set divided by the total number of probes in this probe set. The specificity indicates to what extent the probes of a probe set bind to genes, and it sums the number of probes that match a given gene (assigning lower weight to probes that match additional genes) divided by the total number of probes that match additional genes in a specific manner.

\section{Statistical analysis}

Because some genes are recognized by more than a single probe set, each of which is characterized by an individual specificity and sensitivity that uniquely contribute to the gene expression value, a mean gene expression value was calculated after weighting each probe set for its own sensitivity and specificity, prior to the analysis. Namely, each expression value was multiplied by the semi sum of the sensitivity and specificity of the corresponding probe set. The differential gene expression between HELUs and TDLUs and among histologically normal tissue, ADHs, and DCISs was evaluated using analysis of variance after correction for multiple testing. To correct for multiple testing, the false discovery rate (FDR) with a cut-off of 0.1 was used [14]. All analyses were performed using the open source software R 2.11.1 packages High Dimensional Molecular Data (HDMD; http://www.R-project.org). 


\section{Results}

\section{Genes differentially expressed in HELUs}

Compared with normal TDLUs, HELUs showed differential expression of only 28 genes $(F D R<0.1)$, the majority of which were underexpressed. As shown in Figure 1, the subset included genes encoding proteins typically involved in cell fate decision (ABCG2, JAG2, MYC, NOTCH3, PROM1, SOX9, and SOX10), embryonic development (HOXB2, HOXC10, and HOXC11), cell differentiation (ELF5, FOXA1, and PGR), epigenetic control of gene transcription (EZH1, MLL4, and SMARCA4), and cell adhesion (CDC42, CLDN10, EPCAM, ITGA6, ITGB, and $I T G B 4)$. In addition, the subset included some genes involved in the TGF- $\beta$ signaling pathway (FOXC1 and $T G F B 2$ ) or encoding for growth factors ( $E G F, M F G E 8$, and TGFA) or a cytokine receptor (IL7R).

\section{Genes differentially expressed in ADHs and DCISs}

With respect to histologically normal tissue, ADHs and DCISs were associated, respectively, with 28 and 41 differentially express genes (FDR $<0.1$ ), as shown in Figure 2. Notably, all genes differentially expressed in ADHs were also differentially expressed (in a similar manner) in DCISs, corroborating the hypothesis that $\mathrm{ADH}$ is the biological precursor of DCIS.
Most of the genes in common between ADHs and DCISs encoded proteins involved in cell fate decision (JAG2 and SOX10), embryonic development (HOXA4, HOXA5, HOXA7, HOXA9, and HOXB6), cell differentiation (ELF5 and GATA3) and organization (ACTA2, CD24, CLDN7, $J A M 2$, JAM3, KRT17, MME, and TPJ3), and epigenetic control of gene transcription ( $C B X 8$ and $E Z H 2)$. The set also included genes involved in the canonical and non-canonical TGF- $\beta$ signaling pathways (AKT1, FOXC1, ID2, SNAI2, TGFBR3, and WNT5B) or encoding for growth factors (EGF and $P D G F A$ ) or a growth factor receptor (EGFR). An additional 13 genes were specifically associated with DCISs. The set included ACTL6A that encodes a Trithorax protein (Baf53A) with regulatory activity in several ATP-dependent chromatin-remodeling complexes, 2 members of the claudin adhesion molecule family (CLDN5 and CLDN8), 1 epithelial cell adhesion molecule (EPCAM), 2 basal phenotypeassociated keratins (KRT5 and KRT14), 1 ER (ESR1), 2 cyclins involved in the $G_{2} / M$-phase transition of cell cycle (CCNB1 and CCNB2), 1 cell proliferation-associated antigen (MKI67), 1 chemokine (CXCL12), 1 growth factor (MFGE8), and 1 growth factor receptor (FGFR3).

\section{Genes differentially expressed in HELUs and ADHs/DCISs}

To assess the hypothesis that HELU is the putative biological precursor of ADHs and DCISs, we compared the

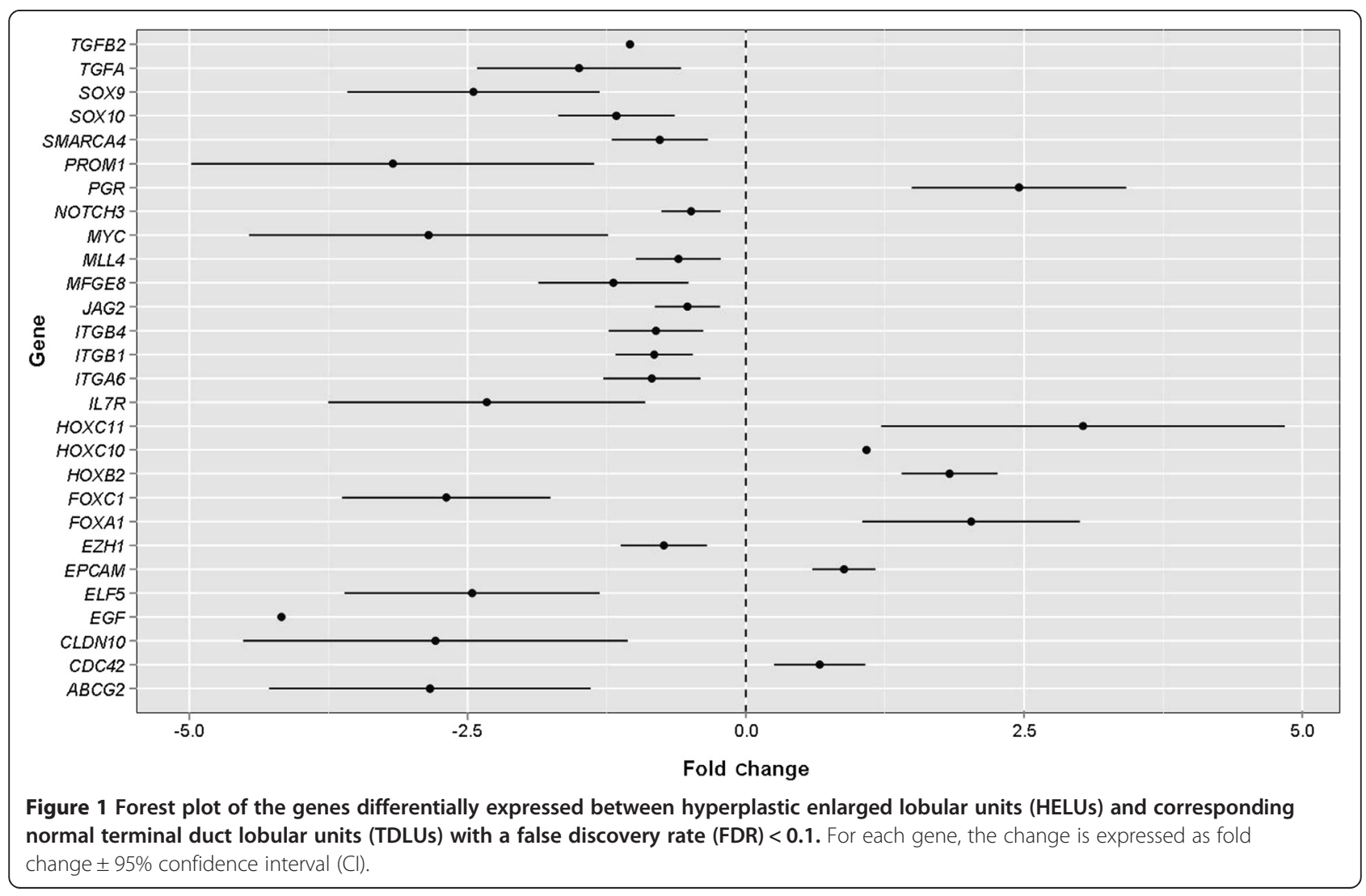




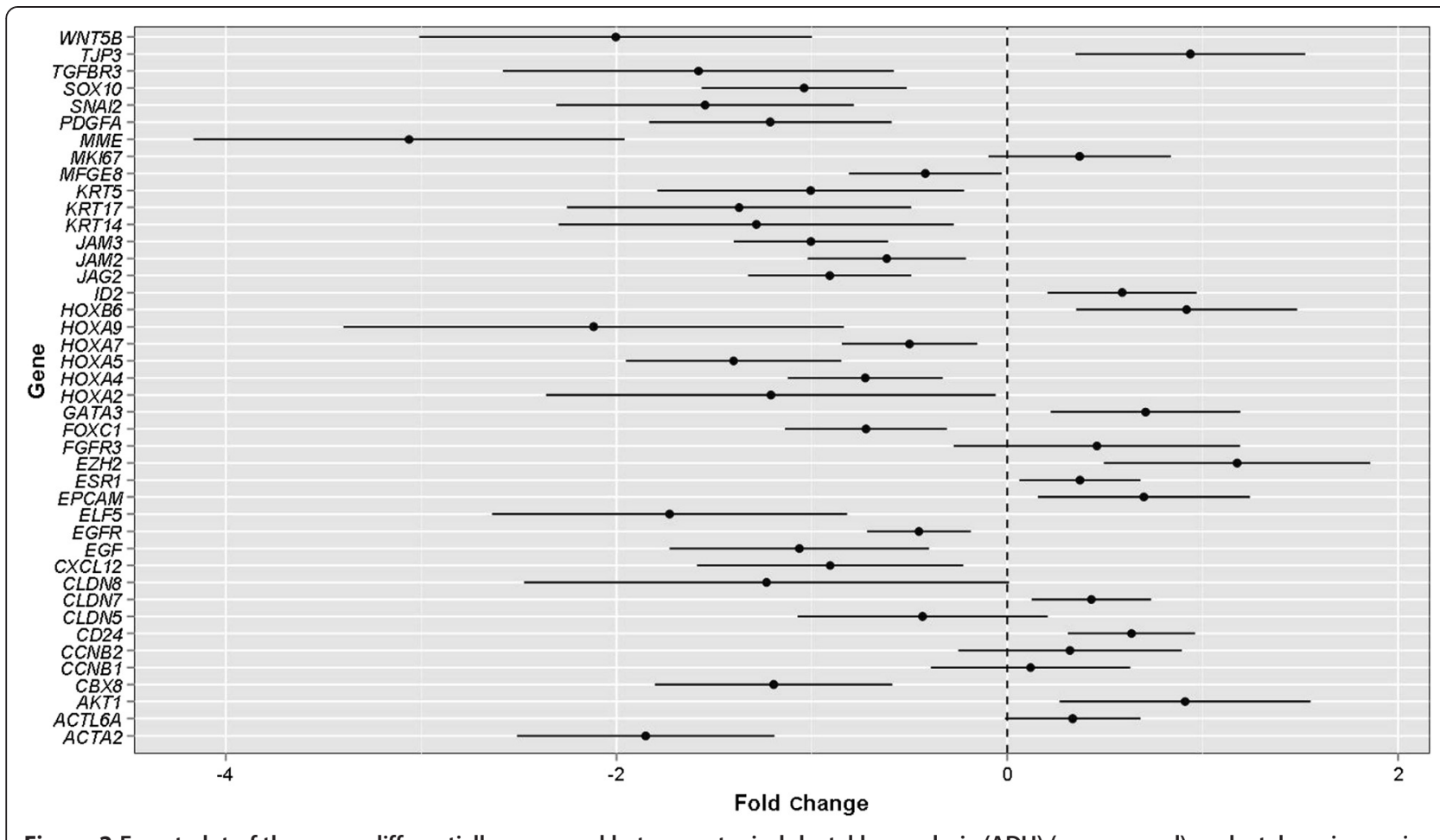

Figure 2 Forest plot of the genes differentially expressed between atypical ductal hyperplasia (ADH) (upper panel) or ductal carcinoma in situ (DCIS) (lower panel) and histologically normal (HN) tissue with a FDR $<0.1$. For each gene, the change is expressed as fold change $\pm 95 \% \mathrm{Cl}$.

panel of genes differentially expressed in HELUs with that of genes differentially expressed in ADHs/DCISs. As shown in Table 1, HELUs and ADHs/DCISs shared a very small subset of genes, which included $E G F, E L F 5$, FOXC1, JAG2, and SOX10, all underexpressed with respect to the corresponding normal tissue.

\section{Discussion}

Overall, the pattern of gene expression in HELUs was consistent with the lobuloalveolar phenotype that characterizes this lesion. In fact, HELUs demonstrated the marked underexpression of genes typically related to the maintenance of a stem-like state, and the concomitant overexpression of genes specifically involved in forming the lobuloalveolar structure. Indeed, genes notably underexpressed in HELUs include ABCG2 and PROM1, which code for 2 stemness-associated markers [15,16], and NOTCH3 and JAG2, which encode Notch receptor 3 and Notch receptor ligand Jagged 2, respectively, 2 elements of the Notch signaling pathway that play a pivotal role in promoting a stem-like state in tumors with a basal phenotype $[17,18]$. Notably, concomitant underexpression of $M Y C$ corroborates the direct relationship between the JAG2-Notch receptor signaling pathway and c-Myc activity. The Notch signaling, in fact, promotes cell survival by regulating the expression of c-Myc transcription factor [19], which in turn, regulates the expression of JAG2 [20] according to a feed- forward-loop transcriptional network. Other genes also underexpressed in HELUs include SOX9 and SOX10, which encode two members of the sex-determining region Y-related (SOX) gene family of transcription factors. The proteins these genes encode are involved, as part of a highly coordinated transcriptional program, in maintaining the stem-like state and in activating the epithelial-to-mesenchymal transition [21,22]. Specifically expressed in myoepithelial cells and breast basal-like carcinomas [23], SOX9 and SOX10 have proven to be negatively associated with FOXA1, which encodes FoxA1 transcription factor, an essential regulator of mammary ductal morphogenesis [24]. Consistent with this evidence, we found that underexpression of SOX9 and SOX10 was associated with FOXA1 overexpression in HELUs. In contrast with SOX9 and SOX10 underexpression, SOX4, another member of SOX gene family that plays a role in commitment to the differentiated luminal phenotype and to be progesterone-regulated [25], was constitutively expressed in HELUs.

In keeping with the physiologic role of progesterone in mammary gland branching morphogenesis [26], a key gene overexpressed in HELUs was PGR, which encodes progesterone receptor, the nuclear ligand-activated receptor required for the canonical genomic mechanism of action of progesterone. Notably, in addition to progesterone receptor, HELUs constitutively expressed PGRMC1 and $P G R M C 2$, which encode progesterone receptor 
Table 1 Genes differentially expressed in HELUs versus TDLUs and ADH/DCIS versus HN tissue with a FDR < 0.1

\begin{tabular}{|c|c|c|c|c|c|}
\hline \multirow{2}{*}{$\begin{array}{l}\text { Gene } \\
\text { symbol }\end{array}$} & \multirow[t]{2}{*}{ Gene name } & \multicolumn{2}{|l|}{ HELUs vs. TDLUs } & \multicolumn{2}{|l|}{ ADH/DCIS vs. HN } \\
\hline & & $\begin{array}{l}\text { Fold change } \\
(95 \% \mathrm{Cl})\end{array}$ & FDR & $\begin{array}{l}\text { Fold change } \\
(95 \% \mathrm{Cl})\end{array}$ & FDR \\
\hline \multicolumn{6}{|c|}{ Common between HELUs and ADH/DCIS } \\
\hline EGF & Epidermal growth factor & $-4.17(\mathrm{ND}, \mathrm{ND})$ & 0.019 & $-1.04(-1.71,-0.37)$ & 0.034 \\
\hline ELF5 & E-74-like factor 5 & $-2.46(-3.60,-1.31)$ & 0.058 & $-1.88(-2.75,-1.00)$ & 0.005 \\
\hline FOXC1 & Forkhead box C1 & $-2.69(-3.63,-1.76)$ & 0.023 & $-0.95(-1.38,-0.51)$ & 0.004 \\
\hline$J A G 2$ & Jagged 2 & $-0.53(-0.82,-0.23)$ & 0.078 & $-0.92(-1.37,-0.48)$ & 0.006 \\
\hline sox10 & SRY (sex determining region Y)-box 10 & $-1.16(-1.69,-0.64)$ & 0.058 & $-1.38(-1.92,-0.85)$ & 0.001 \\
\hline \multicolumn{6}{|c|}{ Exclusive to HELUs } \\
\hline$A B C G 2$ & ATP-binding cassette, sub-family $G$, member 2 & $-2.84(-4.28,-1.39)$ & 0.073 & $-0.62(-1.20,-0.04)$ & 0.149 \\
\hline CDC42 & Cell division cycle 42 & $0.66(0.25,1.07)$ & 0.091 & $0.99(-0.12,0.31)$ & 0.914 \\
\hline CLDN10 & Claudin 10 & $-2.70(-4.52,-1.06)$ & 0.091 & $0.33(-0.26,0.93)$ & 0.864 \\
\hline EPCAM & Epithelial cell adhesion molecule & $0.88(0.60,1.17)$ & 0.019 & $0.14(-0.42,0.69)$ & 0.928 \\
\hline EZH1 & Enhancer of zeste homolog 1 & $-0.74(-1.12,-0.35)$ & 0.073 & $0.12(-0.35,0.58)$ & 0.928 \\
\hline FOXA1 & Forkhead box A1 & $2.03(1.05,3.00)$ & 0.064 & $0.48(-0.28,1.25)$ & 0.855 \\
\hline HOXB2 & Homeobox B2 & $1.83(1.40,2.26)$ & 0.008 & $-0.07(-0.72,0.58)$ & 0.959 \\
\hline HOXC10 & Homeobox C10 & 1.09 (ND, ND) & 0.091 & $0.22(-0.30,0.74)$ & 0.914 \\
\hline HOXC11 & Homeobox C11 & $3.03(1.22,4.84)$ & 0.091 & $0.13(-0.15,0.42)$ & 0.913 \\
\hline IL7R & Interleukin 7 receptor & $-2.33(-3.75,-0.90)$ & 0.091 & $0.23(-0.38,0.84)$ & 0.914 \\
\hline ITGA6 & Integrin, alpha 6 & $-0.85(-1.28,-0.41)$ & 0.073 & $-0.27(-1.15,0.60)$ & 0.914 \\
\hline ITGB1 & Integrin, beta 1 & $-0.82(-1.17,-0.48)$ & 0.049 & $0.58(0.12,1.04)$ & 0.830 \\
\hline ITGB4 & Integrin, beta 4 & $-0.81(-1.23,-0.38)$ & 0.073 & $-0.02(-0.34,0.30)$ & 0.960 \\
\hline MFGE8 & Milk fat globule-EGF factor 8 & $-1.19(-1.87,-0.52)$ & 0.078 & $-0.20(-0.60,0.20)$ & 0.899 \\
\hline MLL4 & Myeloid/lymphoid or mixed-lineage leukemia 4 & $-0.61(-0.99,-0.22)$ & 0.092 & $0.04(-0.60,0.68)$ & 0.960 \\
\hline MYC & v-Myc myelocytomatosis viral oncogene homolog (avian) & $-2.85(-4.46,-1.24)$ & 0.078 & $-0.45(-1.19,0.28)$ & 0.855 \\
\hline NOTCH3 & Notch homolog 3 & $-0.49(-0.76,-0.23)$ & 0.077 & $0.04(-0.22,0.30)$ & 0.959 \\
\hline$P G R$ & Progesterone receptor & $2.46(1.49,3.42)$ & 0.038 & $0.13(-1.21,1.46)$ & 0.959 \\
\hline PROM1 & Prominin 1 & $-3.17(-4.98,-1.36)$ & 0.078 & $-0.78(-1.96,0.40)$ & 0.849 \\
\hline SMARCA4 & $\begin{array}{l}\text { SWI/SNF-related, matrix-associated, actin-dependent } \\
\text { regulator of chromatin, subfamily a, member } 4\end{array}$ & $-0.77(-1.21,-0.34)$ & 0.078 & $0.11(-0.20,0.42)$ & 0.914 \\
\hline soxg & SRY (sex determining region Y)-box 9 & $-2.45(-3.58,-1.31)$ & 0.058 & $-0.26(-1.01,0.49)$ & 0.914 \\
\hline TGFA & Transforming growth factor, alpha & $-1.50(-2.41,-0.58)$ & 0.091 & $-0.08(-0.42,0.25)$ & 0.928 \\
\hline TGFB2 & Transforming growth factor, beta 2 & $-1.04(\mathrm{ND}, \mathrm{ND})$ & 0.092 & $-0.14(-0.71,0.42)$ & 0.928 \\
\hline \multicolumn{6}{|c|}{ Exclusive for ADH/DCIS } \\
\hline ACTA2 & Actin, alpha 2 & $-0.32(-0.71,0.06)$ & 0.353 & $-2.25(-2.95,-1.55)$ & 0.0001 \\
\hline AKT1 & v-Akt murine thymoma viral oncogene homolog 1 & $0.21(-0.65,1.08)$ & 0.798 & $1.07(0.41,1.72)$ & 0.029 \\
\hline CBX8 & Chromobox homolog 8 & $-0.82(-1.55,-0.08)$ & 0.207 & $-0.97(-1.58,-0.37)$ & 0.029 \\
\hline CD24 & CD24 molecule & $0.29(-0.89,1.46)$ & 0.799 & $0.65(0.34,0.95)$ & 0.006 \\
\hline CLDN7 & Claudin 7 & $0.24(\mathrm{ND}, \mathrm{ND})$ & 0.789 & $0.49(0.17,0.82)$ & 0.036 \\
\hline EGFR & Epidermal growth factor receptor & $-0.65(-1.20,-0.09)$ & 0.184 & $-0.62(-0.90,-0.34)$ & 0.004 \\
\hline$E Z H 2$ & Enhancer of zeste homolog 2 & $0.90(-0.31,2.12)$ & 0.412 & $1.61(0.87,2.34)$ & 0.004 \\
\hline GATA3 & GATA-binding protein 3 & $1.12(N D, N D)$ & 0.136 & $0.95(0.47,1.43)$ & 0.008 \\
\hline HOXA4 & Homeobox A4 & $-1.13(-1.92,-0.35)$ & 0.123 & $-0.64(-1.05,-0.22)$ & 0.036 \\
\hline HOXA5 & Homeobox A5 & $-1.40(-2.61,-0.18)$ & 0.189 & $-1.93(-2.50,-1.35)$ & 0.0001 \\
\hline HOXA7 & Homeobox A7 & $-1.54(-2.78,-0.29)$ & 0.174 & $-0.77(-1.14,-0.40)$ & 0.006 \\
\hline
\end{tabular}


Table 1 Genes differentially expressed in HELUs versus TDLUs and ADH/DCIS versus HN tissue with a FDR $<0.1$ (Continued)

\begin{tabular}{|c|c|c|c|c|c|}
\hline HOXA9 & Homeobox A9 & NA & NA & $-3.31(-4.66,-0.96)$ & 0.002 \\
\hline HOXB6 & Homeobox B6 & $0.74(N D, N D)$ & 0.685 & $0.92(0.32,1.52)$ & 0.075 \\
\hline ID2 & Inhibitor of DNA-binding 2 & $-0.34(-1.31,0.64)$ & 0.699 & $0.59(0.21,0.96)$ & 0.063 \\
\hline JAM2 & Junctional adhesion molecule 2 & $-0.62(-2.06,0.82)$ & 0.638 & $-0.91(-1.32,-0.49)$ & 0.004 \\
\hline$J A M 3$ & Junctional adhesion molecule 3 & $-0.55(-1.58,0.49)$ & 0.566 & $-1.09(-1.50,-0.68)$ & 0.001 \\
\hline KRT17 & Keratin 17 & $0.06(-0.65,0.77)$ & 0.948 & $-1.63(-2.56,-0.71)$ & 0.013 \\
\hline$M M E$ & Membrane metallo-endopeptidase & $-0.44(-1.35,0.46)$ & 0.611 & $-4.42(-5.58,-3.25)$ & $<0.001$ \\
\hline PDGFA & Platelet-derived growth factor receptor, alpha polypeptide & $-0.98(-1.77,-0.18)$ & 0.174 & $-1.28(-1.94,-0.63)$ & 0.008 \\
\hline SNAI2 & Snail homolog 2 & $-0.65(-1.58,0.29)$ & 0.439 & $-1.79(-2.59,-0.99)$ & 0.004 \\
\hline TGFBR3 & Transforming growth factor receptor, beta 3 & $-0.85(-1.65,-0.05)$ & 0.229 & $-2.02(-3.09,-0.96)$ & 0.010 \\
\hline TJP3 & Tight junction protein 3 & $-0.47(-0.99,0.04)$ & 0.294 & $1.13(0.51,1.76)$ & 0.013 \\
\hline WNT5B & Wingless-type MMTV integration site family, member 5B & $0.21(-0.86,1.27)$ & 0.864 & $-2.71(-3.75,-1.66)$ & 0.001 \\
\hline
\end{tabular}

HELU, hyperplastic enlarged lobular unit; TDLU, terminal duct lobular unit; ADH, atypical ductal hyperplasia; DCIS, ductal carcinoma in situ; HN, histologically normal; FDR, false discovery rate; $\mathrm{Cl}$, confidence interval; vs., versus; ND, not determined; NA, probe set not available on HG-U133A Human GeneChip microarray.

membrane component 1 and 2, respectively. These proteins mediate the rapid transduction of the progesteroneinduced signaling through a non-genomic mechanism of action [27]. Taken together, these findings support the progesterone dependence of HELUs and explain the peculiar hyperplastic aspect of this lesion.

Our results indicated that $H O X B 2$, HOXC10, and HOXC11 were overexpressed in HELUs. Interestingly, the proteins these genes encode are involved in hormonedependent cell differentiation. HOXB2 is a downstream target of retinoic acid, a well-known differentiation inducer required to maintain the homeostasis of mammary gland morphogenesis [28], and once activated, HOXB2 encodes a transcription factor that negatively regulates growth in breast cancer cells [29]. Similarly, HOXC10 and HOXC11 are transcriptionally regulated sex hormone steroids $[30,31]$, thus justifying their overexpression in HELUs. By contrast, we surprisingly observed underexpression of ELF5, which encodes ELF5, an epithelial-specific transcription factor that plays a crucial role as lineage gatekeeper during normal mammary development by driving the formation of lobuloalveoli from luminal progenitors [32,33]. Notably, we conducted another study of the same genes investigated here, but in normal bipotent progenitors, luminal precursors, and differentiated myoepithelial and luminal differentiated cells [34]. Consistent with the published role of ELF5, we found a positive association between ELF5 expression and luminal commitment and differentiation as well as a negative association between ELF5 expression and myoepithelial cells [34]. Hence, the unexpected underexpression of ELF5 that we observed in HELUs suggests that silencing this gene, possibly via promoter methylation, may be an early event in pathologic transformation. Present results, however, seem to indicate a mechanism of silencing distinct from promoter methylation, as suggested by the underexpression of pivotal genes that function as transcriptional repressors in DNA methylation (EZH1) [35], histone modification (MLL4) [36], or chromatin remodeling (SMARCA4) [37]. A recent study provides an intriguing alternative explanation, demonstrating that progesterone drives mammary differentiation through the receptor activator of necrosis factor kappa B (RANK) ligand-mediated induction of ELF5 in luminal progenitor cells [38]. In fact, in the absence of progesterone, the luminal compartment is composed of mature sensor cells, which express PGR but not ELF5, and mature secretory cells, which express ELF5. After binding its receptor, progesterone induces sensor cells to secrete RANK ligand, the pivotal paracrine mediator of progesterone function [39]. RANK ligand, through ELF expression, then induces epithelial stem cell proliferation and forces asymmetric expansion and differentiation toward the secretory cell lineage of luminal progenitor cells. Present results fit this model well and suggest that HELUs are mainly composed of sensor cells characterized by the concomitant overexpression of $P G R$ and underexpression of ELF5.

Considering the well-differentiated phenotype of HELUs, another apparent paradox was the underexpression of ITGA6 and ITGB4, which respectively encode $\alpha 6$ and $\beta 4$ integrin, the two main components of laminin receptor [40]. However, findings from several immunohistochemical studies provide a convincing explanation for the downregulation of these adhesion molecules. In the normal adult breast, $\alpha 6$ and $\beta 4$ integrins are primarily expressed on the basal surface of myoepithelial cells, where they anchor the underlying basement membrane, and are weakly expressed at the basolateral surface of luminal cells [41]. More detailed studies have shown that cells inside the lobule, which is not surrounded by a basement membrane, do not 
express $\alpha 6$ and $\beta 4$ integrins [42], corroborating the underexpression of ITGA6 and ITGB4 that we observed in HELUs.

Finally, our results are also consistent with a differentiated luminal phenotype in HELUs. We observed underexpression of genes encoding growth factors ( $E G F, M F G E 8$, $T G F A$, and TGFB2) and transcription factors (FOXC1) that are primarily expressed in normal myoepithelium. These genes are also overexpressed in basal-like breast cancers (especially the triple-negative subtype), where they are involved in cell survival, neoangiogenesis, epithelialto-mesenchymal transition, and migration [43-47].

In the gene expression profile for ADHs and DCISs relative to histologically normal tissue, we found a paradoxical association between terminal luminal differentiation (indicated by underexpression of basal marker genes and overexpression of ESR1) and cell proliferation (indicated by overexpression of CCNB1, CCNB2, and MKI67). The finding is particularly significant in understanding the neoplastic transformation process because it contradicts the notion that ER expression and cell proliferation are two dissociated, if not antithetic, processes in normal luminal cells [48]. Per this dissociation principle, estrogen induces never-dividing, ER-positive cells to produce growth factors that stimulate proliferation of adjacent, ER-negative cells in a paracrine manner [49]. Therefore, concomitant overexpression of ESR1, CCNB1, CCNB2, and MIK67 supports the hypothesis that disrupting the mechanism governing the dissociation between ER expression and cell proliferation, and consequently establishing autocrine ER signaling [50], could be a crucial event in the transition from ADHs to DCISs, and provides a molecular explanation of why DCISs have a higher risk of progressing toward invasive cancer. Constitutive expression of ER allows ADH/DCIS-forming cells to exploit, in an autocrine manner, the proliferative stimulus induced by estrogens that bypass the constraint of the ER-proliferation dissociation, and promotes a dividing, ER-dependent, luminal phenotype. Notably, ADH/DCIS-forming cells were characterized by overexpression of FOXA1 and GATA3, which encode two transcription factors (FoxA1 and Gata-3, respectively) that play a pivotal role in estrogen-regulated luminal differentiation and ductal elongation $[24,51]$. In particular, Gata-3, corecruited with FoxA1 to ER cisregulatory elements, is essential for the ER-mediated transcription of target genes as part of a positive feedback loop in which ER expression is required for GATA3 gene transcription [52]. Although FoxA1 and Gata-3 are recognized pioneer transcription factors, their binding capability depends on chromatin modifications. Therefore, the observation that FOXA1 and GATA3 overexpression was associated with ACTL6A and EZH2 overexpression was not surprising, as ACTL6A and EZH2 respectively encode a regulatory component of many ATP-dependent chromatin-remodeling complexes and the inducible catalytic subunit of polycomb repressive complex 2 . However, studies in transgenic mice demonstrated that aberrant overexpression of $E Z H 2$ is associated with disruption of ductal morphogenesis and promotion of hyperplastic epithelium that is predominantly composed of differentiated luminal cells expressing ER and high levels of Gata-3 [53].

We observed a dramatic decrease (up to $90 \%$ in DCISs respect to normal tissue) in $M M E$ expression in ADHs/ DCISs. $M M E$ encodes CD10, a membrane metallopeptidase prevalently expressed in myoepithelium [54]. In normal tissue, myoepithelial cells control mammary gland homeostasis by forming a physical barrier between epithelial cells and the surrounding stroma and secreting paracrine mediators that inhibit cell migration [55]. Because the transition from in situ to invasive carcinoma is associated with the loss of myoepithelial layer, it is conceivable that the progressive underexpression of $M M E$ we observed in ADHs and DCISs represents a very early event in the process of malignant transformation.

When we compared genes that characterize HELUs with genes that characterize ADHs/DCISs, we found that HELUs and ADHs/DCISs shared only 5 genes despite their common luminal origin: EGF, ELF5, FOXC1, JAG2, and SOX10. Each of these genes was underexpressed relative to corresponding normal tissue. The underexpression of all but ELF5 was expected. In fact, EGF underexpression is consistent with experimental evidence that epidermal growth factor supports the development of bipotent cells into both luminal and myoepithelial lineages but decreases during luminal lineage differentiation [56]. Similarly, FOXC1 is specifically expressed in the myoepithelium and overexpressed in ER-negative breast cancers such as the basal-like type, in which it promotes the expression of genes involved in the epithelial-tomesenchymal transition and enhances the propensity to metastasize [57]. Interestingly, recent studies have demonstrated that basal-like breast cancer pathogenesis can be inhibited by the repressive activity of Gata-3 on FOXC1 expression [58] and by the silencing activity of EZH2 [59]. Our results and the aforementioned results show that in both types of precursors (HELUs and ADHs/ DCISs), the underexpression of FOXC1 is associated with the overexpression of GATA3 and $E Z H 2$, suggesting that GATA3 and $E Z H 2$ protect against the transition to an invasive mesenchymal phenotype triggered by FOXC1 overexpression. The underexpression of JAG2 and SOX10 was also unsurprising, because these genes, as previously discussed, are involved in promoting and maintaining the stem-like state. Notably, both genes are specifically expressed in myoepithelial cells and in breast cancers with a basal phenotype $[17,21]$. In regard to $E L F 5$, underexpression interestingly appears to be progesterone-dependent in HELUs but caused by 
gene promoter methylation in ADHs/DCISs (as suggested by the concomitant overexpression of $E Z H 2$ ).

\section{Conclusions}

Although our study has limitations common to the majority of studies involving only gene expression profiling, i.e., small number of cases and lack of validation of the observed mRNA modulations at the protein level, the results we report here provide interesting information. Despite their common luminal origin, HELUs and ADHs/ DCISs are distinct entities, characterized by different gene profiles with very little overlap. In particular, terminal lobular differentiation of HELUs is characterized by overexpression of $P G R$ and constitutive expression of PGRMC1 and PGRMC2 (suggestive of a progesteronedependence), whereas the terminal ductal differentiation of ADHs is characterized by overexpression of ESR1 and GATA3 (suggestive of an estrogen-dependence) and by the unexpected concomitant overexpression of CCNB1, CCNB2, and MKI67. The latter finding is particularly interesting because it supports early disruption of the mechanism governing the dissociation between ER expression and cell proliferation, and the consequent establishment of autocrine ER signaling.

Although clinical evidence indicates that only a small fraction of HELUs and ADHs evolve to invasive cancer, the present findings suggest that exposure to synthetic progestins, frequently administered as hormone-replacement therapy, and estrogens, when abnormally produced by adipose cells and persistently present in the stroma surrounding the mammary gland, must be regarded as potential causes for the development of these hyperplastic lesions.

\section{Competing interests}

The authors declare that they have no competing interests.

\section{Authors' contributions}

DC, FA, PB and EB designed the study; FA and PB analyzed the data; DC, FA, $\mathrm{PB}, \mathrm{SO}$ and $\mathrm{EB}$ discussed the results; $\mathrm{DC}$ and FA wrote the manuscript. All authors read and approved the final manuscript.

\section{Author details}

${ }^{1}$ Department of Clinical Sciences and Community Health, Medical Statistics, Biometry and Bioinformatics, University of Milan, Via Vanzetti 5, Milan 20133, Italy. ${ }^{2}$ Senology Center, Ambrosiana Clinic, Cesano Boscone, Milan 20090, Italy.

Received: 5 May 2014 Accepted: 26 November 2014

Published online: 05 March 2015

\section{References}

1. Lee S, Mohsin SK, Mao S, Hilsenbeck SG, Medina D, Allred DC. Hormones, receptors, and growth in hyperplastic enlarged lobular units: early potential precursors of breast cancer. Breast Cancer Res. 2006;8(1):R6.

2. Schnitt SJ, Vincent-Salomon A. Columnar cell lesions of the breast. Adv Anat Pathol. 2003:10(3):113-24.

3. Oyama T, lijima K, Takei H, Horiguchi J, lino Y, Nakajima T, et al. Atypical cystic lobule of the breast: an early stage of low-grade ductal carcinoma in-situ. Breast Cancer. 2000;7(4):326-31.

4. Dabbs DJ, Carter G, Fudge M, Peng Y, Swalsky P, Finkelstein S. Molecular alterations in columnar cell lesions of the breast. Mod Pathol. 2006;19(3):344-9.
5. Shaaban AM, Sloane JP, West CR, Moore FR, Jarvis C, Williams EMI, et al. Histopathologic types of benign breast lesions and the risk of breast cancer: case-control study. Am J Surg Pathol. 2002;26(4):421-30.

6. Lakhani SR, Slack DN, Hamoudi RA, Collins N, Stratton MR, Sloane JP. Detection of allelic imbalance indicates that a proportion of mammary hyperplasia of usual type are clonal, neoplastic proliferations. Lab Invest. 1996;74(1):129-35.

7. Brock HW, Fisher CL. Maintenance of gene expression patters. Dev Dynamics. 2005;232(3):633-55.

8. Ringrose L, Paro R. Epigenetic regulation of cellular memory by the Polycomb and Trithorax group proteins. Annu Rev Genet. 2004;38:413-43.

9. Vermaak D, Ahmad K, Henkoff S. Maintenance of chromatin states: an open-and-shut case. Curr Opin Cell Biol. 2003;15(3):266-74.

10. Hake SB, Xiao A, Allis CD. Linking the epigenetic "language" of covalent histone modifications to cancer. Br J Cancer. 2004;90(4):761-9.

11. Lee S, Medina D, Tsimelzon A, Mohsin SK, Mao S, Wu Y, et al. Alteration of gene expression in the development of early hyperplastic precursors of breast cancer. Am J Pathol. 2007;171(1):252-62.

12. Emery LA, Tripathi A, King C, Kavanah M, Mendez J, Stone MD, et al. Early dysregulation of cell adhesion and extracellular matrix pathway in breast cancer progression. Am J Pathol. 2009;175(3):1292-302.

13. Ferrari F, Bortoluzzi S, Coppe A, Sirota A, Safran M, Shmoish M, et al. Novel definition files for human GeneChip based on GeneAnnot. BMC Bioinformatics. 2007;8:446.

14. Benjamini $Y$, Hochberg Y. Controlling the false discovery rate. A practical and powerful approach to multiple testing. J Royal Stat Soc. 1995;57:284-300.

15. Zhou S, Schuetz JD, Bunting KD, Colapietro AM, Sampath J, Morris JJ, et al. The $A B C$ transporter Bcrp1/ABCG2 is expressed in a wide variety of stem cells and is a molecular determinant of the side-population phenotype. Nat Med. 2001;7(9):1028-34.

16. Wu Y, Wu PY. CD133 as a marker for cancer stem cells: progresses and concerns. Stem Cells Dev. 2009;18(8):1127-34.

17. Reedijk M, Pinnaduwage D, Dickson BC, Mulligan AM, Zhang H, Bull SB, et al. JAG1 expression is associated with a basal phenotype and recurrence in lymph node-negative breast cancer. Breast Cancer Res Treat. 2008;111(3):439-48.

18. Xing F, Okuda H, Watabe M, Kobayashi A, Pai SK, Liu W, et al. Hypoxiainduced Jagged 2 promotes breast cancer metastasis and self-renewal of cancer stem-like cells. Oncogene. 2011;30(39):4075-86.

19. Palomero T, Lim WK, Odom DT, Sulis ML, Real PJ, Margolin A, et al. NOTCH1 directly regulates C-MYC and activates a feed-forward-loop transcriptional network promoting leukemic cell growth. Proc Natl Acad Sci U S A. 2006:103(48):18261-6.

20. Yustein JT, Liu YC, Gao P, Jie C, Le A, Vuica-Ross M, et al. Induction of ectopic Myc target gene JAG2 augments hypoxic growth and tumorigenesis in a human B-cell model. Proc Natl Acad Sci U S A. 2010;107(8):3534-9.

21. Ivanov SV, Panaccione A, Nonaka D, Prasad ML, Boyd KL, Brown B, et al. Diagnostic SOX10 gene signatures in salivary adenoid cystic and breast basal-like carcinomas. Br J Cancer. 2013;109(2):444-51.

22. Guo W, Keckesova Z, Donaher JL, Shibue T, Tischler V, Reinhardt F, et al. Slug and Sox9 cooperatively determine the mammary stem cell state. Cell. 2012;148(5):1015-28.

23. Cimino-Mathews A, Subhawong AP, Elwood H, Warzecha HN, Sharma R, Ho Park B, et al. Neural crest transcription factor Sox10 is preferentially expressed in triple-negative and metaplastic breast carcinomas. Hum Pathol. 2013;44(6):959-65.

24. Bernardo GM, Lozada KL, Miedler JD, Harburg G, Hewitt SC, Mosley JD, et al. FOXA1 is an essential determinant of ERa expression and mammary ductal morphogenesis. Development. 2010;137(12):2045-54.

25. Graham JD, Hunt SM, Tran N, Clarke CL. Regulation of the expression and activity by progestins of a member of the SOX gene family of transcriptional modulators. J Mol Endocrinol. 1999;22(3):295-304.

26. Lain AR, Creighton CJ, Connelly OM. Research resource: progesterone receptor targetome underlying mammary gland branching morphogenesis. Mol Endocrinol. 2013;27(10):1743-61.

27. Peluso JJ. Non-genomic actions of progesterone in the normal and neoplastic mammalian ovary. Semin Reprod Med. 2007;25(3):198-207.

28. Wang YA, Shen K, Wang Y, Brooks SC. Retinoic acid signaling is required for proper morphogenesis of mammary gland. Dev Dyn. 2005;234(4):892-9.

29. Boimel PJ, Cruz C, Segall JE. A functional in vivo screen for regulators of tumor progression identifies HOXB2 as a regulator of tumor growth in breast cancer. Genomics. 2011;98(3):164-72. 
30. Ansari Kl, Hussain I, Kasiri S, Mandal SS. HOXC10 is overexpressed in breast cancer and transcriptionally regulated by estrogen via involvement of histone methylases MLL3 and MLL4. J Mol Endocrinol. 2012;48(1):61-75.

31. Ma L, Benson GV, Lim H, Dey SK, Maas RL. Abdominal B (AbdB) Hoxa genes: regulation in adult uterus by estrogen and progesterone and repression in müllerian duct by the synthetic estrogen diethylstilbestrol (DES). Dev Biol. 1998;197(2):141-54.

32. Oakes SR, Naylor MJ, Asselin-Labat ML, Blazek KD, Gardiner-Garden M, Hilton $\mathrm{HN}$, et al. The Ets transcription factor Elf5 specifies mammary alveolar cell fate. Genes Dev. 2008;22(5):581-6.

33. Ng RK, Dean W, Dawson C, Lucifero D, Madeja Z, Reik W, et al. Epigenetic restriction of embryonic cell lineage fate by methylation of Elf5. Nat Cell Biol. 2008;10(11):1280-90.

34. Coradini D, Boracchi P, Oriana S, Biganzoli E, Ambrogi F. Differential expression of genes involved in the epigenetic regulation of cell identity in normal human mammary cell commitment and differentiation. Chin J Cancer. 2014;33(10):501-10.

35. Spermann A, van Lohuizen M. Polycomb silencers control cell fate, development and cancer. Nat Rev Cancer. 2006;6(11):846-56.

36. Mo R, Rao SM, Zhu YJ. Identification of MLL2 complex as a coactivator for estrogen receptor alpha. J Biol Chem. 2006;281(23):15714-20.

37. Eberharter A, Becker PB. ATP-dependent nucleosome remodeling: factors and functions. J Cell Sci. 2004;117(Pt17):3707-11.

38. Lee HJ, Gallego-Ortega D, Ledger A, Schramek D, Joshi P, Szwarc MM, et al. Progesterone drives mammary secretory differentiation via RankL-mediated induction of Elf5 in luminal progenitor cells. Development. 2013;140 (7):1397-401.

39. Gonzalez-Suarez E, Jacob AP, Jones J, Miller R, Roudier-Meyer MP, Erwert R, et al. RANK ligand mediates progestin-induced mammary epithelial proliferation and carcinogenesis. Nature. 2010;468(7320):103-7.

40. Green KJ, Jones JC. Desmosomes and hemidesmosomes: structure and function of molecular components. FASEB J. 1996;10(8):871-81.

41. Koukoulis GK, Virtanen I, Korhonen M, Laitinen L, Quaranta V, Gould VE. Localization of integrins in the normal, hyperplastic, and neoplastic breast. Correlations with their functions as receptors and cell adhesion molecules. Am J Pathol. 1991;139(4):787-99.

42. Damjanovich L, Fülöp B, Adány R, Nemes Z. Integrin expression on normal and neoplastic human breast epithelium. Acta Chir Hung. 1997;36(1-4):69-71.

43. Nicholson Rl, Gee JMW, Harper ME. EGFR and cancer prognosis. Eur J Cancer. 2001;37 Suppl 4:S9-15.

44. Carrascosa C, Obula RG, Missiaglia E, Lehr HA, Delorenzi M, Frattini M, et al. MFG-E8/lactadherin regulates cyclins D1/D3 expression and enhances the tumorigenic potential of mammary epithelial cells. Oncogene. 2012;31 (12):1521-32.

45. Booth BW, Smith $\mathrm{GH}$. Roles of transforming growth factor-al pha in mammary development and disease. Growth Factors. 2007;25(4):227-35.

46. Dave H, Trivedi S, Shah M, Shukla S. Transforming growth factor beta 2: a predictive marker for breast cancer. Indian J Exp Biol. 2011;49(11):879-87.

47. Ray PS, Wang J, Qu Y, Sim MS, Shamonki J, Bagaria SP, et al. FOXC1 is a potential prognostic biomarker with functional significance in basal-like breast cancer. Cancer Res. 2010;70(10):3870-6.

48. Clarke RB, Howell A, Potten CS, Anderson E. Dissociation between steroid receptor expression and cell proliferation in the human breast. Cancer Res. 1997;57(22):4987-91.

49. Mallepell S, Krst A, Chambon P, Brisken C. Paracrine signaling through the epithelial estrogen receptor $a$ is required for proliferation and morphogenesis in the mammary gland. Proc Natl Acad Sci U S A. 2006;103 (7):2196-201.

50. Tan $H$, Zhong $Y$, Pan Z. Autocrine regulation of cell proliferation by estrogen receptor-a in estrogen receptor-a-positive breast cancer cell lines. BMC Cancer. 2009;9:31.

51. Asselin-Labat ML, Sutherland KD, Barker H, Thomas R, Shackleton M, Forrest NC, et al. Gata-3 is an essential regulator of mammary-gland morphogenesis and luminal-cell differentiation. Nat Cell Biol. 2007;9(2):201-9.

52. Eeckhoute J, Keeton EK, Lupien M, Krum SA, Carroll JS, Brown M. Positive cross-regulatory loop ties GATA-3 to estrogen receptor a expression in breast cancer. Cancer Res. 2007;67(13):6477-82.

53. Li X, Gonzalez ME, Toy K, Filzen T, Merajver SD, Kleer CG. Targeted overexpression of EZH2 in the mammary gland disrupts ductal morphogenesis and causes epithelial hyperplasia. Am J Pathol. 2009;175(3):1246-54.
54. Kenny AJ, O'Hare MJ, Gusterson BA. Cell-surface peptidases as modulators of growth and differentiation. Lancet. 1989;2(8666):785-7.

55. Jones JL, Shaw JA, Pringle JH, Walker RA. Primary breast myoepithelial cells exert an invasion-suppressor effect on breast cancer cells via paracrine down-regulation of MMP expression in fibroblasts and tumour cells. J Pathol. 2003;201(4):562-72.

56. Csanaky K, Doppler W, Tamas A, Kovacs K, Toth G, Reglodi D. Influence of terminal differentiation and PACAP on the cytokine, chemokine, and growth factor secretion of mammary epithelial cells. J Mol Neurosci. 2014;52(1):28-36.

57. Sizemore ST, Keri RA. The forkhead box transcription factor FOXC1 promotes breast cancer invasion by inducing matrix metalloprotease 7 (MMP7) expression. J Biol Chem. 2012;287(29):24631-40.

58. Tkocz D, Crawford NT, Buckley NE, Berry FB, Kennedy RD, Gorski JJ, et al. BRCA1 and GATA3 corepress FOXC1 to inhibit the pathogenesis of basal-like breast cancers. Oncogene. 2012;31(32):3667-78.

59. Du J, Li L, Ou Z, Kong C, Zhang Y, Dong Z, et al. FOXC1, a target of polycomb, inhibits metastasis of breast cancer cells. Breast Cancer Res Treat. 2012;131(1):65-73.

\section{Submit your next manuscript to BioMed Central and take full advantage of:}

- Convenient online submission

- Thorough peer review

- No space constraints or color figure charges

- Immediate publication on acceptance

- Inclusion in PubMed, CAS, Scopus and Google Scholar

- Research which is freely available for redistribution 